\title{
Lack of sphingomyelin synthase 2 reduces cerebral ischemia/reperfusion injury by inhibiting microglial inflammation in mice
}

\author{
YU YANG*, FENGXIAN HU*, GUIFENG YANG and QINGMEI MENG \\ Department of Radiology, The Third People's Hospital of Qingdao, Qingdao, Shandong 266041, P.R. China
}

Received December 17, 2018; Accepted August 21, 2020

DOI: $10.3892 /$ etm.2020.9371

\begin{abstract}
Recanalization of blood flow after ischemia can lead to ischemia/reperfusion injury, and inflammation plays an important role in the mechanisms behind cerebral ischemia/reperfusion injury. Sphingomyelin synthase 2 (SMS2) deficiency reduces inflammation; however, the effect and mechanism of action of SMS2 on the inflammatory response after cerebral ischemia/reperfusion injury are still unclear. Wild-type (WT) and SMS2 knockout C57BL/6 mice were used to establish a model of cerebral ischemia/reperfusion. The neurological deficit score was evaluated with Longa's method, and infarct volume was evaluated by magnetic resonance imaging and 2,3,5-triphenyltetrazolium chloride staining. Neurological deficit and infarct volume were used to evaluate the degree of cerebral ischemia/reperfusion injury in mice. Western blotting, reverse transcription-quantitative PCR and immunofluorescence were used to detect the expression profiles. The neurological deficit score of SMS2 $2^{-/}$mice was significantly lower than that of WT mice at $72 \mathrm{~h}$ after cerebral ischemia/reperfusion injury $(\mathrm{P}=0.027)$, but not significantly different at $24 \mathrm{~h}(\mathrm{P}=0.064)$. Compared with WT mice at 24 and $72 \mathrm{~h}$ after cerebral ischemia/reperfusion, the infarct volume of $\mathrm{SMS}^{-/-}$mice was decreased, the expression of pro-inflammatory cytokines galectin 3 and interleukin- $1 \beta$ were decreased, the activation of microglia was decreased, and the nuclear translocation of NF- $\kappa \mathrm{B}$ p 65 was decreased, but the expression of the anti-inflammatory factor arginase 1 was increased. Lack of SMS2 in mice can help to reduce the inflammatory reaction by inhibiting the activation of $N F-\kappa B$ signaling pathway, further attenuating cerebral ischemia/reperfusion injury in mice.
\end{abstract}

Correspondence to: Dr Qingmei Meng, Department of Radiology, The Third People's Hospital of Qingdao, 29 Yongping Road, Licang, Qingdao, Shandong 266041, P.R. China

E-mail: mengqm157@163.com

*Contributed equally

Key words: sphingomyelin synthase 2, cerebral ischemia reperfusion, microglial, inflammation

\section{Introduction}

The brain is the most sensitive organ to ischemia and hypoxia, and cerebral ischemia can lead to necrosis or apoptosis of brain cells. Timely thrombolysis, rapid and effective reconstruction of collateral circulation of microvessels and recovery of blood reperfusion in ischemic regions and the penumbra are the best treatment for cerebral ischemia (1). However, recanalization of blood flow after ischemia can lead to ischemia/reperfusion injury. During ischemic/reperfusion, there are a large number of inflammatory factors synthesized and secreted in the ischemic area. The activation and infiltration of inflammatory cells, and the synthesis and secretion of adhesion molecules are part of a positive feedback cascade that enhance and promote each other (2). These responses signal through a specific inflammatory signaling pathway, converting ischemic brain tissues into inflammatory lesions $(3,4)$. Therefore, inflammation plays an important role in the mechanism of cerebral ischemia/reperfusion injury.

Sphingomyelin (SM) is an important component of cell membranes, mainly located in cell membranes, lipoproteins and other lipid-rich tissue structures. SM is widely found in biological tissues and is abundant in brain tissue (5). Previous studies have shown that products and key enzymes in the metabolism of SM are involved in many aspects of cerebral ischemia $(6,7)$ and play an important role in the development of cerebral ischemia $(8,9)$. Therefore, the regulation of the SM metabolic pathway is expected to be a new target for the treatment of ischemic cerebrovascular disease.

SM synthase (SMS) is the last enzyme in the SM synthesis pathway. SMS has two isoenzymes, SMS1 and SMS2 (10). SMS1 mainly exists in the Golgi apparatus, and SMS2 mainly exists in the plasma membrane, with SMS2 being widely expressed in brain tissue (10).

Previous studies have found that SMS2 is an important regulatory factor in inflammatory responses $(11,12)$. SMS2 deficiency inhibits the activation of $N F-\kappa B$ pathways in macrophages induced by lipopolysaccharide (LPS) (13), which intimates that SMS2 may be involved in the regulation of inflammatory responses. However, the effect and mechanism of action of SMS2 on the inflammatory response after cerebral ischemia/reperfusion injury are still unclear, and remains to be further studied. Therefore, this present study used wild-type and SMS2 knockout C57BL/6 mice as research subjects to 
explore the role of SMS2 in cerebral ischemia/reperfusion injury in mice, and to study its specific molecular mechanisms.

\section{Materials and methods}

Animals and experimental groups. Male wild-type (WT) C57BL/6 mice (8-12 weeks; 25-30 g; Cyagen Biosciences, Inc.) and SMS2 knockout (SMS2 ${ }^{-/}$) mice (Cyagen Biosciences, Inc.) in the background of wild-type C57BL/6 mice (8-12 weeks; 25-30 g) were acclimatized for 1 week at room temperature $\left(20-24^{\circ} \mathrm{C}\right)$ with free access to water/food and $45-60 \%$ humidity in a $12 \mathrm{~h} \mathrm{light/dark} \mathrm{cycle.} \mathrm{A} \mathrm{total} \mathrm{of} 26 \mathrm{WT}$ mice and 26 SMS2-/- were used in the present study. Mice were divided into two subgroups: Sham group and middle cerebral artery occlusion (MCAO) group. The present study was performed with the approval of the Ethics Committee of The Third People's Hospital of Qingdao.

Cerebral ischemia/reperfusion model. Longa's method (14) was used to establish the cerebral ischemia/reperfusion mouse model. Mice were injected intraperitoneally with $4 \%$ chloral hydrate (Sinopharm Chemical Reagent Co., Ltd.) at a ratio of $350 \mathrm{mg} / \mathrm{kg}$, for anesthesia. Mice were fixed in a supine position and monitored to ensure breathing was unobstructed. Mouse necks were sterilized with an ethanol-soaked cotton ball and a $1-\mathrm{cm}$ incision was made in the neck. Under a stereo microscope, the submandibular glands were dissected, the right common carotid artery, external and internal carotid arteries were freed up, and the common carotid artery was tied with a thread. At the bifurcation of the external carotid artery and the common carotid artery, a loose knot was made with silk; the distal end of the external carotid artery was ligated with silk, and the external carotid artery was fused with an electric coagulation pen. The internal carotid artery was fastened with a silk thread, the external carotid artery was cut with microscopic surgical scissors to insert a thread plug through the small hole to the external carotid artery, and the line knot on the internal carotid artery was loosened. The plug was slowly inserted in the direction of the internal carotid artery until the resistance was reached. To prevent bleeding, the external carotid artery was tied up. After $2 \mathrm{~h}$ of ischemia, the plug was pulled out and the arterial blood was allowed to circulate again for $24 \mathrm{~h}$. The surgical procedure in the sham group was the same as before, however the line plug was not inserted. Post-surgery, animals were maintained at $25-28^{\circ} \mathrm{C}$, with access to food and water ad libitum.

Evaluation of neurological deficits. The neurological deficit in the mice was evaluated with reference to Longa's method (14): 0 points, no symptoms of neurological deficits and normal activity; 1 point, contralateral forelimbs cannot fully extend; 2 points, circling to the contralateral side when crawling; 3 points, body dumping to the hemiparalysis side when walking; 4 points, not autonomous walking and loss of consciousness was 4 points; 5 points, death. If the score was 1-4, the model was considered successful.

Determination of infarct volume. Magnetic resonance imaging (MRI) and 2,3,5-triphenyltetrazolium chloride (TTC) staining were used to detect the infarct volume.
MRI. Mice were injected intraperitoneally with $4 \%$ chloral hydrate at $350 \mathrm{mg} / \mathrm{kg}$ to be anesthetized. The Phillips GyroscanIntera 1.5T MRI (Phillips Medical Systems B. V.) and the rat coil (Shanghai Chenguang Medical Technology Co., Ltd.) were used for fast spin echo T2-weighted (FSE T2W) imaging. The parameters used were as follows: Time of Repetition was $1,600 \mathrm{msec}$; Time of Echo was $80 \mathrm{msec}$; slice thickness was $1 \mathrm{~mm}$; slice gap was 0 ; Field of View was 35x35 mm; and matrices were 256x256. ImageJ software (version 1.41; National Institutes of Health) was used to measure the area of cerebral infarction per layer. The percentage cerebral infarction volume was calculated via the following formula: Percentage cerebral infarction volume $=(\mathrm{S} 1+\mathrm{S} 2+\mathrm{S} 3+\mathrm{SN}) \mathrm{H} /(\mathrm{S} 1$ total $+\mathrm{S} 2$ total $+\mathrm{S} 3$ total + SN total), where S1-SN were the infarct sizes of each layer, S1 total-SN total were the areas of brain tissue in each layer, and $\mathrm{H}$ was slice thickness (15).

TTC staining. Mice were sacrificed immediately after MRI scans, and the brains were dissected immediately. The brain tissue of mice was frozen for $20 \mathrm{~min}$ in a $-20^{\circ} \mathrm{C}$ refrigerator, and then cut into 2 -mm-thick continuous slices. Slices were incubated at $37^{\circ} \mathrm{C}$ for $15-30$ min with $2 \%$ TTC (Sigma-Aldrich; Merck KGaA) in a darkroom. They were then fixed with $4 \%$ paraformaldehyde (Sinopharm Chemical Reagent Co., Ltd.) at room temperature for $15 \mathrm{~min}$. ImageJ software was used to assess the area of cerebral infarction per layer (16). The cerebral infarction volume was calculated by multiplying the infarct size of each brain slice by the thickness $(2 \mathrm{~mm})$ using a Leica TCS SP5 fluorescent microscope (Leica Microsystems, $\mathrm{GmbH})$.

Reverse transcription-quantitative PCR (RT- $q P C R)$. Each group of mice was anesthetized with $4 \%$ chloral hydrate at 24 and $72 \mathrm{~h}$ after the surgery. The mice were decapitated and the infarcted penumbra was harvested under aseptic conditions. Brain tissue was rapidly homogenized in RNAiso Plus (Takara Biotechnology Co., Ltd.) within a glass homogenizer (Shanghai Broadcom Chemical Technology Co., Ltd.). Total RNA from brain tissue was extracted according to the TRIzol RNA total extraction method. RNA was dissolved in diethylpyrocarbonate-treated water (Takara Biotechnology Co., Ltd.), and RNA concentration was measured with a NanoDrop 2,000 Ultramicro Spectrophotometer (Thermo Fisher Scientific, Inc.). The extracted RNA was reverse transcribed into cDNA by using a PrimeScript ${ }^{\mathrm{TM}} \mathrm{RT}$ master mix reverse transcription kit (cat. no. RR036B; Takara Biotechnology Co., Ltd.). Reverse transcriptase parameters were as follows: $37^{\circ} \mathrm{C}$ for $60 \mathrm{~min}$, $85^{\circ} \mathrm{C}$ for $5 \mathrm{sec}$. RNA samples $(20 \mu \mathrm{l})$ were prepared with SYBR Green according to the SYBR-Green qPCR Master Mix kit instructions (cat. no. 638320; Takara Biotechnology Co., Ltd.) and amplified using the Applied Biosciences 7500 fluorescence PCR system (Thermo Fisher Scientific, Inc.). PCR parameters were as follows: $95^{\circ} \mathrm{C}$ for $30 \mathrm{sec}, 90^{\circ} \mathrm{C}$ for $5 \mathrm{sec}, 65^{\circ} \mathrm{C}$ for $30 \mathrm{sec}$, for 40 cycles. $\beta$-actin was used as the internal control and the relative expression level of the target gene was calculated by $2^{-\Delta \Delta \mathrm{Cq}}$ method (17). The primers used were as follows: Galectin forward, 5'-TTTCAGGAGAGGGAATGATGTTG-3' and reverse, 5'-CACAATGACTCTCCTGTTGTTCTCA-3'; arginase 1 (Arg1) forward, 5'-CTCCAAGCCAAAGTCCTT 
AGAG-3' and reverse, 5'-GGAGCTGTCATTAGGGACATC A-3'; inducible nitric oxide synthase (iNOS) forward, 5'-CTC TTCGACGACCCAGAAAAC-3' and reverse, 5'-CAAGGC CATGAAGTGAGGCTT-3'; IL-1 $\beta$ forward, 5'-GAAATGCCA CCTTTTGACAGTG-3' and reverse, 5'-TGGATGCTCTCA TCAGGACAG-3'; $\beta$-actin forward, 5'-TCACCCACACTG TGCCCATCTACG-3' and reverse, 5'-CAGCGGAACCGC TCATTGCCAATG-3'.

Western blotting. Brain tissue was submerged in RIPA lysate, containing $1 \mathrm{mM}$ PMSF (Beyotime Institute of Biotechnology) and rapidly homogenized within a glass homogenizer, then placed on ice for $10 \mathrm{~min}$, and centrifuged at $13,800 \mathrm{x} \mathrm{g}$ for $10 \mathrm{~min}$ and the supernatant was isolated, which contained the total tissue protein.

Harvest buffer [10 mmol/1 HEPES, pH 7.9; $50 \mathrm{mmol} / \mathrm{l}$ $\mathrm{NaCl} ; 1 \mathrm{mmol} / 1 \mathrm{EDTA} ; 0.5 \%$ Triton X-100; $1 \mathrm{mmol} / \mathrm{l}$ dithiothreitol (DTT), $0.5 \mathrm{~mol} / 1$ sucrose, $1 \mathrm{mmol} / \mathrm{l} \mathrm{PMSF}]$ and brain tissue were homogenized within a glass homogenizer, and then placed on ice for $10 \mathrm{~min}$, centrifuged at $13,800 \mathrm{xg}$ for $10 \mathrm{~min}$ at room temperature and the supernatant was isolated, which contained the cytoplasmic proteins. Centrifugal sediment was washed with buffer A (10 mmol/1 HEPES, pH 7.9; $10 \mathrm{mmol} / 1$ $\mathrm{KCl} ; 0.1 \mathrm{mmol} / \mathrm{l}$ EDTA; $0.1 \mathrm{mmol} / \mathrm{l} \mathrm{EGTA;} 1 \mathrm{mmol} / \mathrm{l} \mathrm{DTT}$; $1 \mathrm{mmol} / \mathrm{l} \mathrm{PMSF})$. This solution was centrifuged $(13,800 \mathrm{x} \mathrm{g}$ for $10 \mathrm{~min}$ at room temperature) again and the supernatant was removed. The supernatant was resuspended in buffer $\mathrm{C}$ (10 mmol/l HEPES, pH 7.9; $500 \mathrm{mmol} / \mathrm{l} \mathrm{NaCl} ; 0.1 \mathrm{mmol} / \mathrm{l}$ EDTA; $0.1 \mathrm{mmol} / 1$ EGTA; 0.1\% Igepal; $1 \mathrm{mmol} / 1 \mathrm{DTT}$; $1 \mathrm{mmol} / \mathrm{l} \mathrm{PMSF}$ ), and then placed on ice for $15 \mathrm{~min}$. The solution was centrifuged at $13,800 \mathrm{x} \mathrm{g}$ for $10 \mathrm{~min}$ at room temperature and the supernatant was isolated, which contained the nuclear protein.

Buffer solution containing 20\% SDS was added to the supernatant until the final concentration of SDS was $1 \%$, and the mixture was boiled at $100^{\circ} \mathrm{C}$ for $5 \mathrm{~min}$. The concentration of protein was determined by bicinchoninic acid protein concentration assay kit (Beyotime Institute of Biotechnology). A mass of $75 \mu \mathrm{g}$ of total protein was loaded into each lane and separated by $15 \%$ SDS-PAGE ( $90 \mathrm{~V}$ for $0.5 \mathrm{~h} ; 120 \mathrm{~V}$ for $1 \mathrm{~h}$ ) and transferred (400 mA for $1.5 \mathrm{~h}$ ) to polyvinylidene fluoride film (GE Healthcare Life Sciences), fixed with methanol for $1 \mathrm{~min}$ at room temperature, washed three times ( 5 min each) with TBST (10 mM Tris-HCl; $150 \mathrm{mM} \mathrm{NaCl} ; 0.1 \%$ Tween-20, pH 7.6) and blocked with blocking buffer (5\% skim milk in TBST) for $1 \mathrm{~h}$ at room temperature. Anti-galectin 3 (cat. no. ab76245; Abcam; 1:1,000), anti-NF-кB-p65 (cat. no. ab16502; Abcam; 1:1,000), anti-lamin A (cat. no. ab8980; Abcam; $1: 1,000$ ), or anti- $\beta$-actin antibody (cat. no. ab8227; Abcam; 1:2,000) diluted in 5\% skim milk was added and incubated at $4{ }^{\circ} \mathrm{C}$ overnight, followed by washing with TBST three times ( 10 min each). Sheep anti-rabbit secondary antibody (cat. no. ab205718; Abcam; 1:2,000) or sheep anti-mouse secondary antibody (cat. no. ab6808; Abcam; 1:2,000) was added and incubated for $1 \mathrm{~h}$ at room temperature, and then ECL solution (Sigma-Aldrich; Merck KGaA) was added for detection. The expression of the target protein was analyzed by ImageJ software (National Institutes of Health), and the relative expression level of target protein was characterized by the gray value of the target protein/gray value of $\beta$-actin or lamin A protein.
Immunofluorescence. Each group of mice was anesthetized with $4 \%$ chloral hydrate at 24 and $72 \mathrm{~h}$ after surgery. The chest was cut to expose the heart. The injection needle was then inserted into the left ventricle and the right atrial appendage was cut. Rapid perfusion with $100 \mathrm{ml}$ normal saline 100 was performed, followed by perfusion and fixation with $200 \mathrm{ml}$ of $4 \%$ paraformaldehyde. The brain was dissected immediately after perfusion. The brain tissue was fixed in a $4 \%$ paraformaldehyde solution for $24 \mathrm{~h}$ at $4^{\circ} \mathrm{C}$, dehydrated by sucrose gradient treatment, embedded in optimal cutting temperature compound at $4^{\circ} \mathrm{C}$ (Beijing Transgen Biotech Co., Ltd.), and serially sectioned with a cryostat, to a thickness of $30 \mu \mathrm{m}$.

Brain tissue sections were removed and left at room temperature for $20 \mathrm{~min}$. After drying, the areas of immunohistochemistry were marked. Rinsing was performed three times (5 min each) with PBS solution ( $135 \mathrm{mM} \mathrm{NaCl}, 2.7 \mathrm{mM} \mathrm{KCl}$, $1.5 \mathrm{mM} \mathrm{KH}_{2} \mathrm{PO}_{4}, 8 \mathrm{mM} \mathrm{K}_{2} \mathrm{HPO}_{4}, \mathrm{pH}=7.2$ ) at room temperature. After being blocked with $100 \%$ goat serum (HyClone; GE Healthcare Life Sciences) at $37^{\circ} \mathrm{C}$ for $1 \mathrm{~h}$, the goat serum was removed and sections were incubated with anti-galectin 3 (cat. no. ab76245; Abcam; 1:1,000) and anti-allograft inflammatory factor 1 (Iba 1) antibody (cat. no. ab178847; Abcam; $1: 100)$ at $4^{\circ} \mathrm{C}$ overnight. Rinsing was performed three times (5 min each) with PBS solution at room temperature in the dark. Sections were then incubated with the goat anti-mouse secondary antibody-Alexa Fluor Plus 488 (cat. no. A32723; 1:500; Thermo Fisher Scientific, Inc.) or goat anti-mouse secondary antibody-Alexa Fluor Plus 594 (cat. no. A32742; 1:500; Thermo Fisher Scientific, Inc.) at $37^{\circ} \mathrm{C}$ for $1 \mathrm{~h}$, rinsed three times (5 min each) with PBS at room temperature in dark, mounted and observed with a fluorescence microscope (Carl Zeiss AG).

Statistical analysis. The data were analyzed with the SPSS 20.0 software package (IBM Corp.) and the data are expressed as the mean \pm standard deviation. Student's t-tests were used to compare the differences between two groups. One-way ANOVA with Duncan's post-hoc test was used for comparing multiple groups. $\mathrm{P}<0.05$ was considered to indicate a statistically significant difference.

\section{Results}

Lack of SMS2 attenuates cerebral ischemia/reperfusion injury in mice. The neurological deficit score in different mice at 24 or $72 \mathrm{~h}$ after MCAO was evaluated by the Longa grading criteria (14). As shown in Fig. 1I, there was no significant difference in neurological deficit score between the two groups of mice at $24 \mathrm{~h}$ after cerebral ischemia/reperfusion injury $(\mathrm{P}=0.064)$, but the neurological deficit score was significantly lower in SMS2 ${ }^{--}$mice compared with WT mice at $72 \mathrm{~h}$ after cerebral ischemia/reperfusion injury $(\mathrm{P}=0.027)$.

TTC staining and MRI was used to detect the infarct volume of MCAO mice after cerebral ischemia/reperfusion. After TTC staining, the normal brain tissue was uniformly red and infarcted brain tissue was white (Fig. 1A-D). With MRI, infarcts showed high signal through FSE T2W imaging (Fig. 1E-H). At 24 and $72 \mathrm{~h}$ after cerebral ischemia/reperfusion, TTC staining showed a wide range of white infarct areas in the infarct cortex and basal ganglia, which was same as MRI in WT and SMS2-/2 

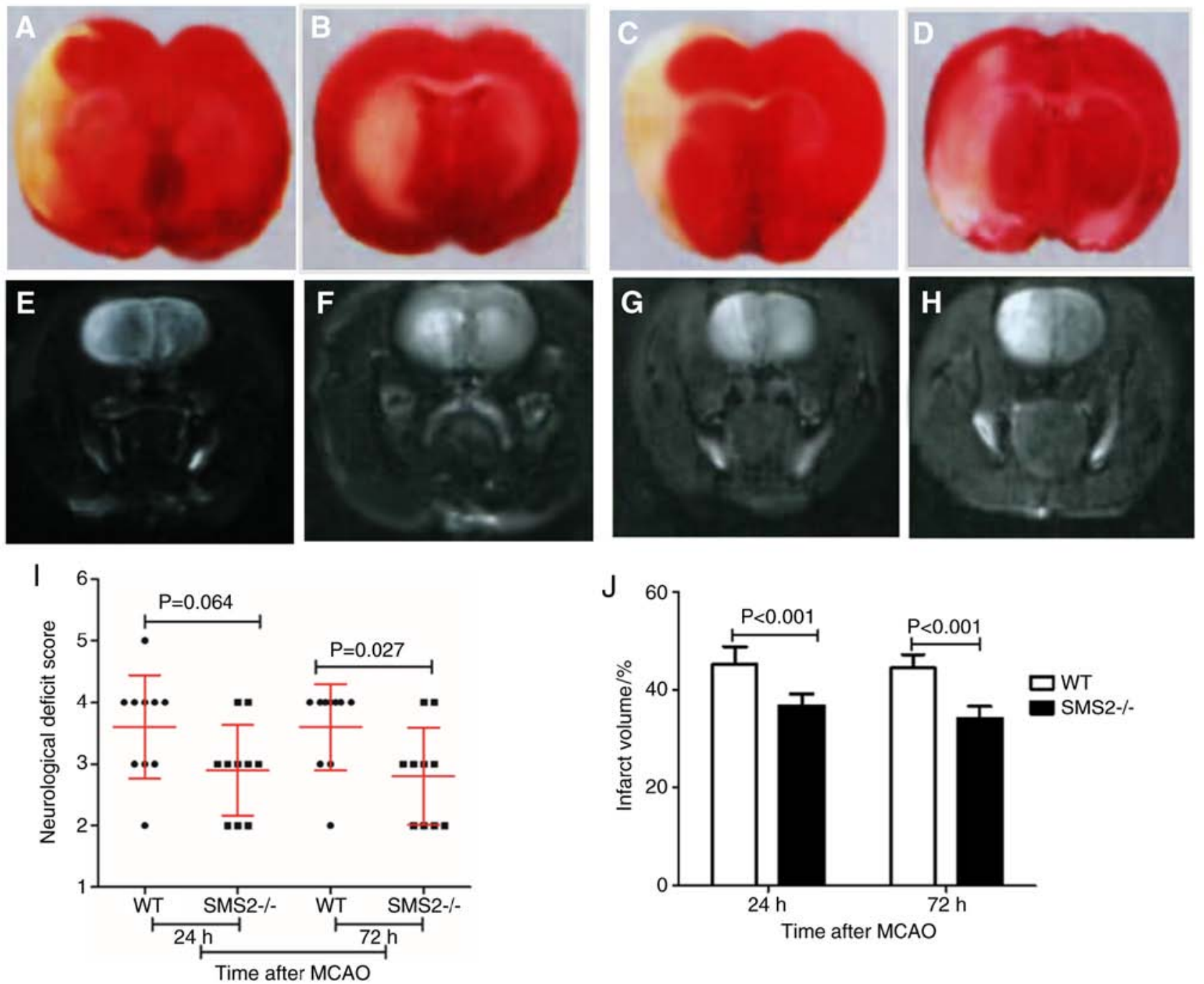

Figure 1. Lack of SMS2 reduces the neurological score and infarct volume in MCAO mice after cerebral ischemia/reperfusion ( $\mathrm{n}=10)$. Infarct volume of (A) WT MCAO mice and (B) SMS2 ${ }^{-/}$at $24 \mathrm{~h}$; and (C) WT MCAO mice and (D) SMS2 ${ }^{-/}$at $72 \mathrm{~h}$ after MCAO was detected by triphenyltetrazolium chloride staining. Infarct volume of (E) WT MCAO mice and (F) SMS2 ${ }^{--}$at 24; (G) WT MCAO mice and (H) SMS2 $2^{-/}$at $72 \mathrm{~h}$ after MCAO was detected by MRI. (I) The neurological score of different mice at different time after MCAO. (J) The infarct volume of the WT and SMS2 ${ }^{--}$mice at 24 and $72 \mathrm{~h}$ after MCAO. MCAO, middle cerebral artery occlusion; SMS, sphingomyelin synthase; WT, wild-type.

mice. Infarct volumes of SMS2 ${ }^{-\digamma} \mathrm{MCAO}$ mice were significantly smaller than those of WT MCAO mice $(\mathrm{P}<0.05$; Fig. $1 \mathrm{~J})$.

Lack of SMS2 attenuates the expression of inflammatory mediators. The inflammatory pathways that are mediated by the Toll-like receptor (TLR) family play an important role in the inflammatory response induced by cerebral ischemia (18). Galectin 3, an endogenous ligand for TLR4 (19), plays an important role in the inflammatory response after organ ischemia $(20,21)$. Western blotting was used to detect the expression of galectin 3 protein, and the results showed that galectin 3 protein expression was increased at 24 and $72 \mathrm{~h}$ after cerebral ischemia/reperfusion in mice compared to sham mice, with $\mathrm{SMS}^{-/}$group MCAO mice expressing significantly lower levels of galectin 3 than those in the WT group MCAO mice $(\mathrm{P}<0.001$; Fig. $2 \mathrm{~A}$ and $\mathrm{B})$.

Moreover, the expression of inflammatory mediators of cerebral ischemia/reperfusion in mice was detected by RT-qPCR (Fig. 2C and D). At 24 and $72 \mathrm{~h}$ after cerebral ischemia/reperfusion in mice, the expression of pro-inflammatory cytokines galectin 3 and IL-1 $\beta$ was significantly increased $(\mathrm{P}<0.001)$, and the $\mathrm{SMS}^{--}$group MCAO mice expressed significantly lower levels of both mRNAs than the WT group MCAO mice at both time points $(\mathrm{P}<0.001)$. The expression of anti-inflammatory factor Arg 1 was significantly increased after cerebral ischemia/reperfusion $(\mathrm{P}<0.001)$, and the $\mathrm{SMS}^{-1-}$ group MCAO mice expressed significantly higher levels than the WT group MCAO mice at both time points $(\mathrm{P}<0.001)$. While anti-inflammatory factor iNOS was also significantly increased $(\mathrm{P}<0.001)$ at $24 \mathrm{~h}$ after ischemia/reperfusion, there was no significant difference in iNOS mRNA levels at $72 \mathrm{~h}$ in either the WT or $\mathrm{SMS}^{-/}$groups $(\mathrm{P}>0.05)$.

Lack of SMS2 inhibits the activation of microglia. Microglia are activated soon after cerebral ischemia/reperfusion injury and are the main cells that cause serious inflammation $(22,23)$. Iba 1 is a protein that is specifically expressed on microglia $(24,25)$. Therefore, immunofluorescence staining was used to count the number of Iba 1-positive cells, which was used to characterize the activation of microglia after cerebral 

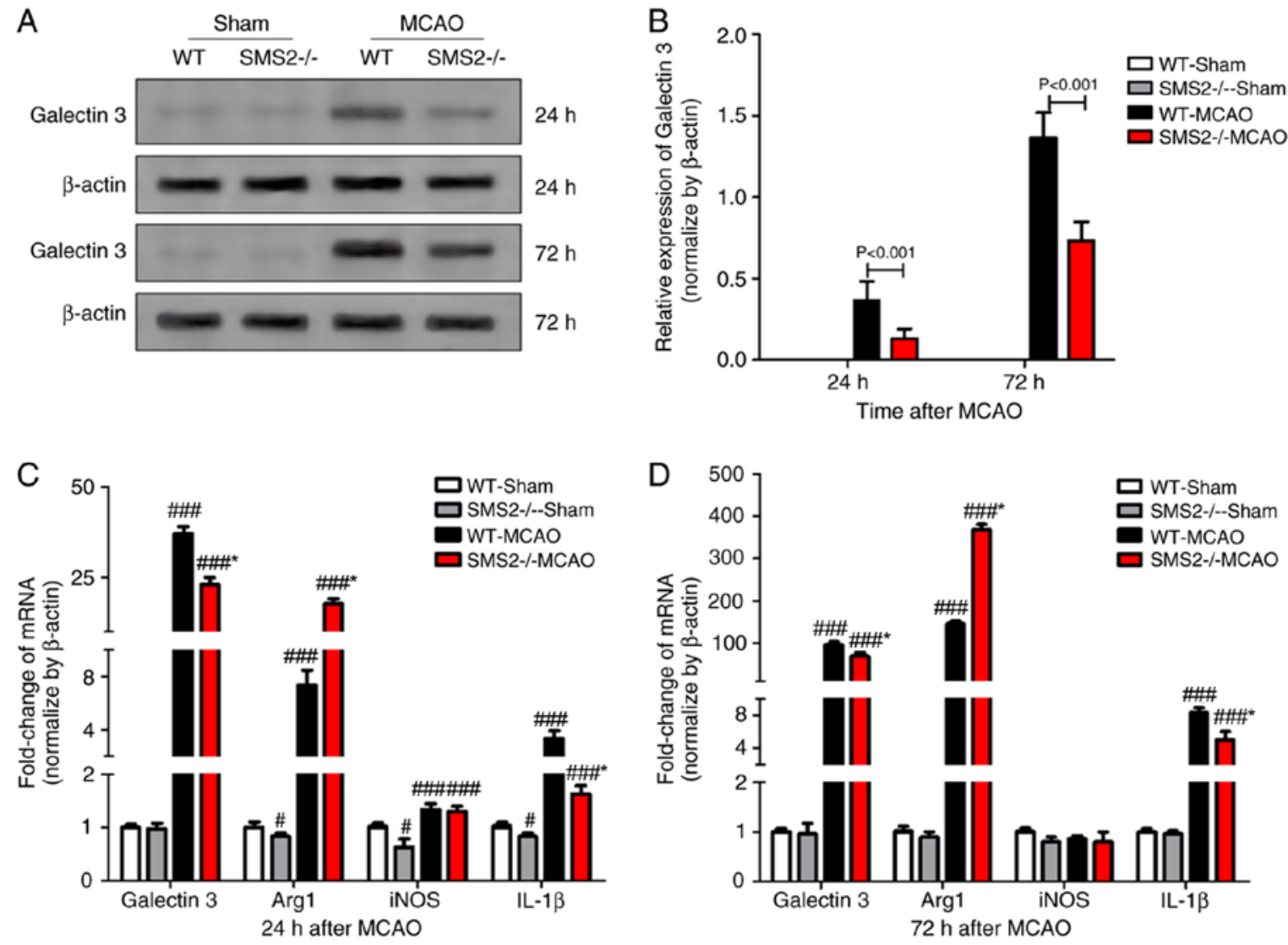

Figure 2. Lack of SMS2 attenuates expression of inflammatory mediators after cerebral ischemia/reperfusion ( $\mathrm{n}=3$ ). (A) Western blotting was used to detect the expression of galectin 3 protein in different WT and SMS2 ${ }^{-/}$mice at 24 and $72 \mathrm{~h}$ after MCAO. (B) Quantification of western blot bands by grayscale comparison. Reverse transcriptase quantitative PCR was used to detect the expression of galectin 3 , Arg1, iNOS and IL-1 $\beta$ mRNA in different mice at (C) 24 or (D) $72 \mathrm{~h}$ after MCAO. ${ }^{~ P} \mathrm{P}<0.05,{ }^{\# \# \#} \mathrm{P}<0.001$ vs. WT-Sham group; ${ }^{*} \mathrm{P}<0.05$ vs. WT-MCAO group. Arg1, arginase 1; IL, interleukin; iNOS, inducible nitric oxide synthase; MCAO, middle cerebral artery occlusion; SMS, sphingomyelin synthase; WT, wild-type.

ischemia/reperfusion. As shown in Fig. 3, the number of Iba 1+ cells in $\mathrm{SMS}^{-/-}$mice was significantly lower than that in WT mice following MCAO at both 24 and $72 \mathrm{~h}(\mathrm{P}<0.05)$. Similarly, the number of galectin $3^{+} / \mathrm{Iba} 1^{+}$cells significantly decreased at 24 and $72 \mathrm{~h}$ after cerebral ischemia/reperfusion $(\mathrm{P}<0.05$ and $\mathrm{P}<0.001$ respectively).

Lack of SMS2 inhibits the activation of the $N F-\kappa B$ pathway. The expression of NF- $\mathrm{B}$ p 65 protein in nuclear and cytoplasmic fractions was observed by western blotting. At 24 and $72 \mathrm{~h}$ after cerebral ischemia/reperfusion, the expression of $\mathrm{NF}-\kappa \mathrm{B}$ p65 protein in the nucleus of $\mathrm{SMS}^{-/-}$mice was significantly lower than that in WT mice $(\mathrm{P}<0.001)$, but the opposite was observed in the cytoplasm $(\mathrm{P}<0.001$; Fig. 4). These data indicate that the nuclear translocation of $N F-\kappa B$ p65 is significantly reduced in $\mathrm{SMS}^{-/-}$mice after ischemia/reperfusion, when compared with WT MCAO mice.

\section{Discussion}

$\mathrm{SMS} 2^{-/-}$mice were obtained by knocking out intron $1(1.1 \mathrm{~kb})$, exon $2(0.7 \mathrm{~kb})$ and intron $2(6.2 \mathrm{~kb})$ in the SMS2 gene of C57BL/6J mice. There was no difference in living habits between C57BL/6J mice (26). In this present study, WT and SMS2 knockout C57BL/6J were the research subjects studied. This study found that SMS2 $2^{-/}$mice not only had lower neurological deficit scores than WT mice after ischemia/reperfusion, but also had a significantly lower infarct volume than WT mice. This indicated that a lack of SMS2 attenuated cerebral ischemia/reperfusion injury in mice.

In addition, a previous study indicated (27) that SMS2 deficiency inhibits LPS-induced inflammatory responses by impeding activation of the $\mathrm{NF}-\kappa \mathrm{B}$ signaling pathway. Therefore, this present study examined the expression of inflammatory mediators such as galectin $3, \operatorname{Arg} 1$, iNOS and IL-1 $\beta$ in the infarcted brain after cerebral ischemia/reperfusion in mice. The results showed that after cerebral ischemia/reperfusion, the expression of both pro-inflammatory and inhibitory factors increased, and the expression of pro-inflammatory cytokines in the SMS2 ${ }^{--}$group MCAO mice was lower than that in the WT MCAO mice, but the expression of anti-inflammatory cytokines in the SMS2 $2^{-/}$group MCAO mice was higher than that in WT MCAO mice. This suggested that SMS2 deficiency might reduce ischemia/reperfusion injury in mice by reducing inflammatory responses after cerebral ischemia/reperfusion.

Microglia are macrophages in the central nervous system, and their activation is a hallmark of neuroinflammation. Microglia in the normal mature brain are stationary. Resting microglia become active after central nervous system damage. The activated microglia mediate neurotoxic effects by releasing a series of inflammatory cytokines, proteins and other biologically active substances, and causing secondary brain 
A
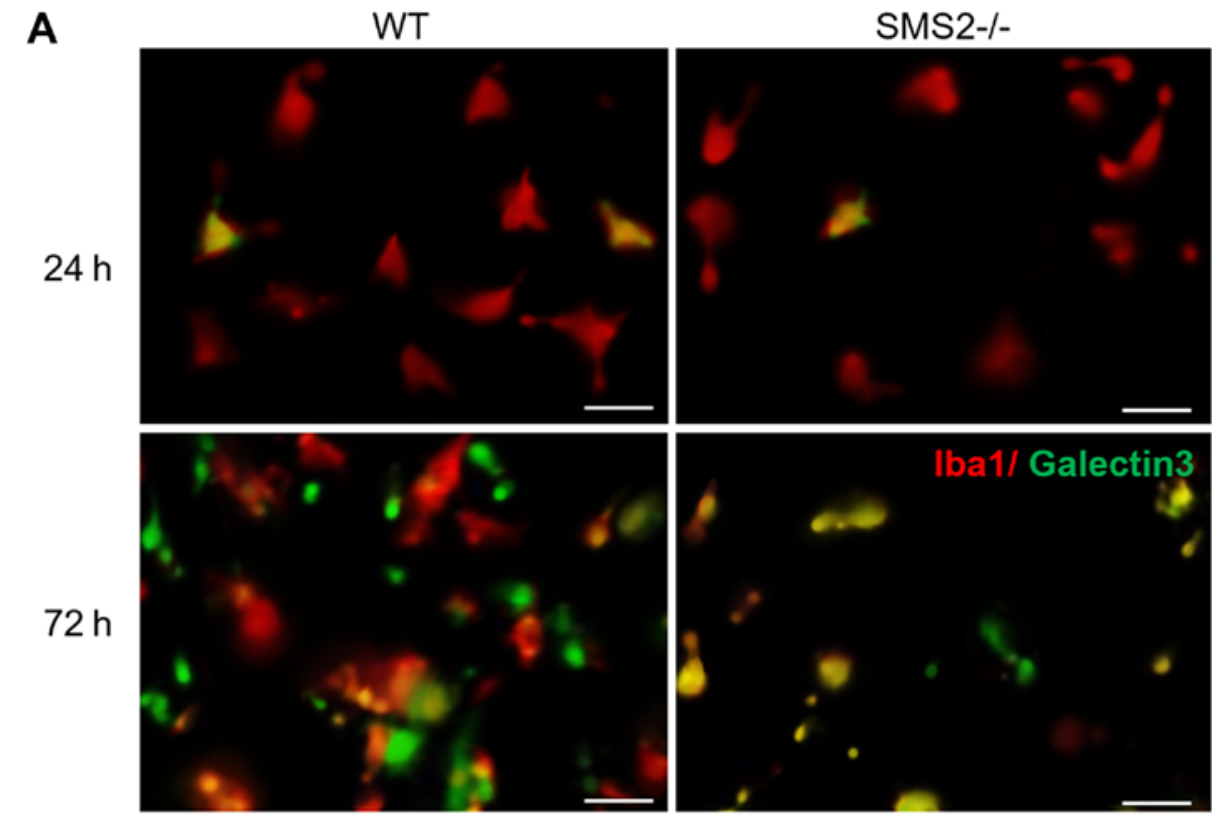

B
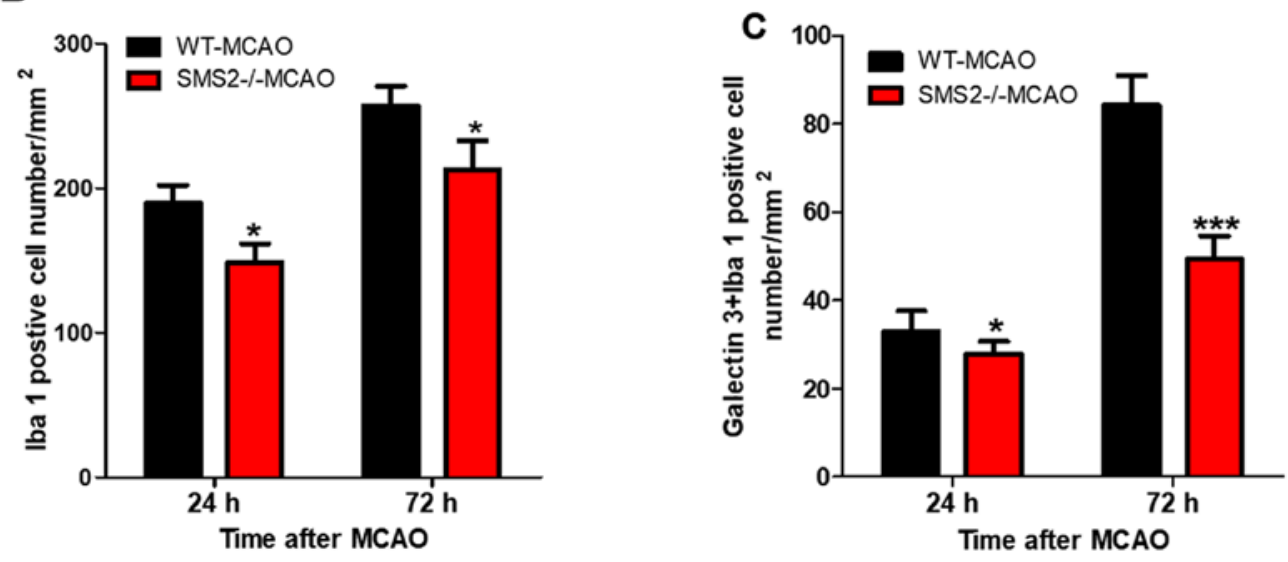

Figure 3. Lack of SMS2 reduces the number of Iba 1 and galectin 3/Iba 1-positive cells after cerebral ischemia/reperfusion (n=3). (A) Immunofluorescence was used to detect the Iba 1 or galectin 3/Iba 1 positive cells in different mice at 24 or $72 \mathrm{~h}$ after MCAO. The counts of (B) Iba 1 and (C) galectin 3/Iba 1 positive cell in different mice at 24 or $72 \mathrm{~h}$ after MCAO. ${ }^{*} \mathrm{P}<0.05,{ }^{* * * *} \mathrm{P}<0.001 \mathrm{vs}$. the WT-MCAO group. Scale bars, $10 \mu \mathrm{m}$. Iba 1, allograft inflammatory factor 1; MCAO, middle cerebral artery occlusion; SMS, sphingomyelin synthase; WT, wild-type.

injury $(28,29)$. Moon et al $(30)$ used immunohistochemistry to examine the temporal changes in the activation of microglia after transient cerebral ischemic injury, and they found that microglia were activated $3 \mathrm{~h}$ after cerebral ischemia/reperfusion. Microglial activation state reached a peak 2 days after cerebral ischemia/reperfusion.

A previous study has shown that microglia can play a protective role by regulating the expression of receptors, proteins or cytokines after cerebral ischemia injury (31). Microglia can produce tumor necrosis factor (TNF). Lambertsen et al (31) confirmed that TNF that was secreted by microglia played a neuroprotective role in the acute phase of focal cerebral ischemic injury through TNF-p55 receptor. This present study found that the number of Iba $1^{+}$and galectin $3^{+} / \mathrm{Iba} 1^{+}$ cells in $\mathrm{SMS2}^{-/-}$mice after cerebral ischemia/reperfusion was significantly lower than that in WT mice $(\mathrm{P}<0.05)$. Iba 1 is a specific surface antigen for microglia, and the decreased Iba $1^{+}$ cells in $\mathrm{SMS}^{-/-}$mice after cerebral ischemia/reperfusion indicate a decrease in microglial activation in SMS2 ${ }^{-/}$mice after ischemia/reperfusion. The decreased galectin $3^{+} / \mathrm{Iba}^{+}$ cells indicate a decrease in the inflammatory response which is associated with activated microglial galectin 3. After focal cerebral ischemia, many pro-inflammatory cytokines, chemokines, and leukocyte adhesion molecules are upregulated, and signal transduction by the cells was necessary for the pathogenesis and pathological development (32). TLRs, NF- $\mathrm{KB}$, Mitogen-activated protein kinases, and the JNK-STAT signaling pathway are the most widely studied pathways which are involved in the transduction of cerebral ischemia/reperfusion inflammation (32). This present study has shown that the expression of galectin 3 protein in SMS2 $2^{-/}$mice was significantly lower than that of WT mice after ischemia/reperfusion. Galectin 3 is an endogenous ligand of TLR4 (33). TLR4 binds to its ligand to form the TLR/myeloid differentiation-2 (MD2) complex that activates downstream inflammatory pathways (33). This study also found that the expression of TLR4/MD2 on the surface of microglia was decreased in $\mathrm{SMS}^{-/}$mice $72 \mathrm{~h}$ after cerebral ischemia/reperfusion injury, but there was no significant difference in the expression of TLR4. This suggests that SMS2 deficiency may inhibit 
A
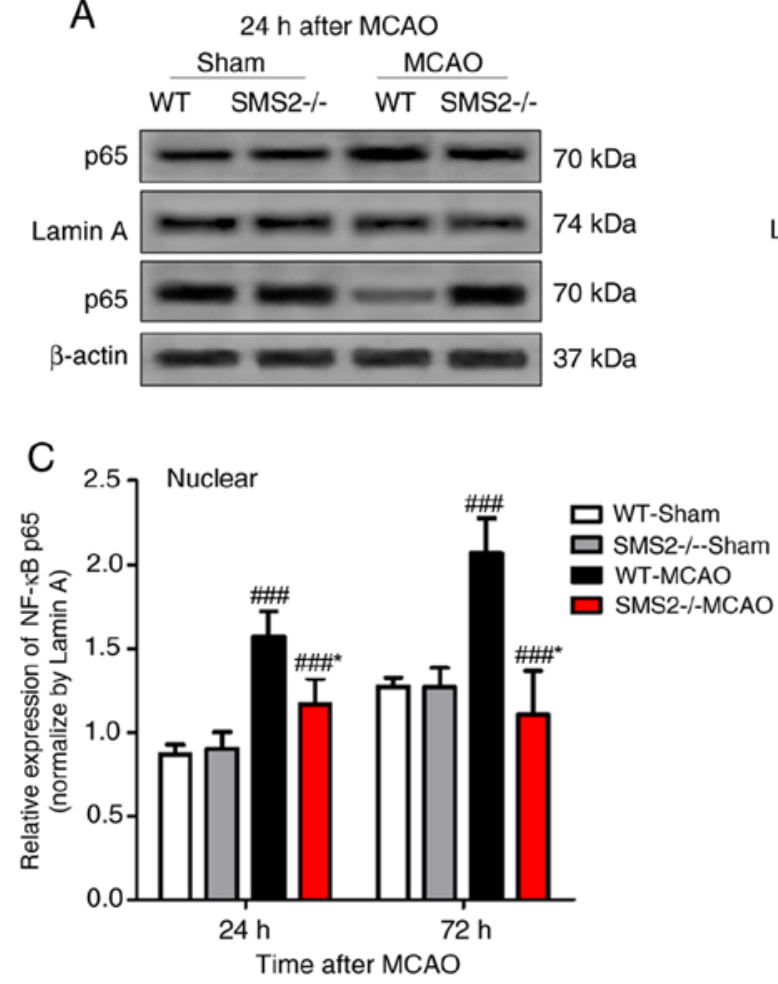

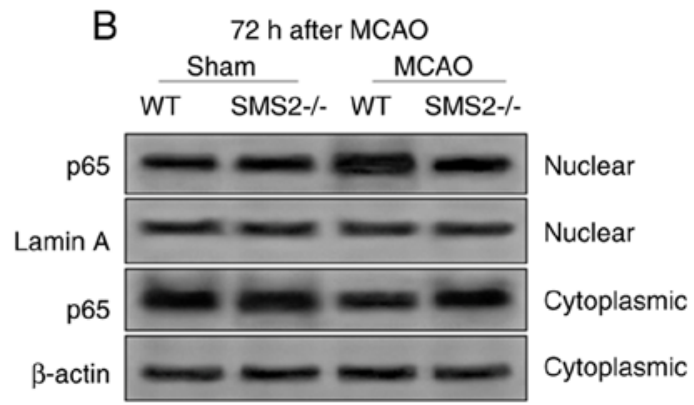

D

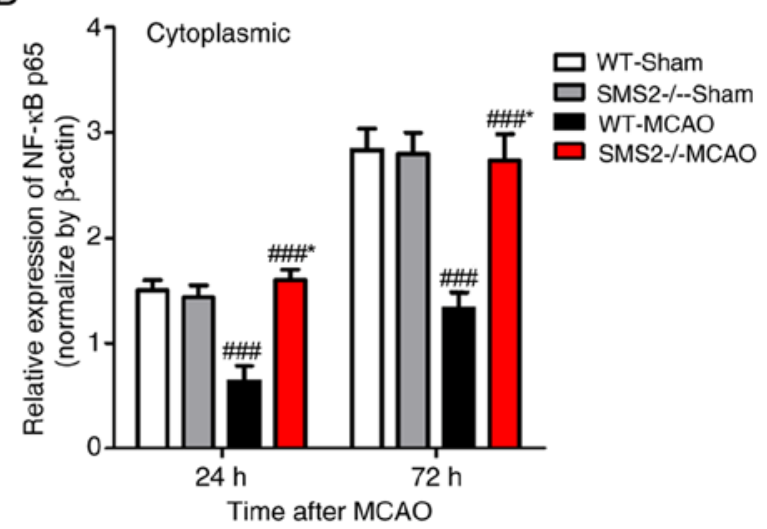

Figure 4. Lack of SMS2 blocks nuclear translocation of NF- $\mathrm{B}$ p65 after cerebral ischemia/reperfusion. Western blotting was used to detect the expression of NF- $\kappa$ B-p65 protein levels in the nucleus and the cytoplasm at (A) 24 and (B) $72 \mathrm{~h}$ after cerebral ischemia/reperfusion in the peri-infarct region of WT and $\mathrm{SMS}^{-/-}$mice. Quantification of western blots at (C) 24 and (D) $72 \mathrm{~h}$ by grayscale comparison. ${ }^{\# \# \#} \mathrm{P}<0.001$ vs WT-Sham group; ${ }^{*} \mathrm{P}<0.05$ vs. WT-MCAO group. $\mathrm{NF}-\kappa \mathrm{B}$, nuclear factor $\kappa$-light-chain-enhancer of activated B cells; SMS, sphingomyelin synthase; WT, wild-type.

subsequent inflammatory responses by reducing TLR4/MD2 complex formation after cerebral ischemia/reperfusion injury, rather than reducing TLR4 expression. The TLR family is a family of pathogen-associated molecular pattern receptors that recognize and bind to conserved sequences of pathogenic microorganisms (33). These are receptors that mediate bacterial endotoxin LPS-induced inflammation. As this present study progressed, TLRs were also found to be involved in cerebral ischemia/reperfusion inflammatory induced injury (34). The brain is a sterile organ, and inflammatory damage to the brain is mainly transduced through the TLR pathway (34). DNA and protein detection of TLRs was performed in normal mice and mice with cerebral ischemia/reperfusion injury. The DNA and protein content of TLR2 and TLR4 in mice with cerebral ischemia/reperfusion injury were significantly higher than those in a normal group in a previous study (35). TLRs mediate NF- $\kappa \mathrm{B}$ activation, and $\mathrm{NF}-\kappa \mathrm{B}$ upregulates the expression of inflammatory factors, causing inflammatory damage.

$\mathrm{NF}-\kappa \mathrm{B}$ belongs to the Rel protein family and is an important signal transduction molecule involved in inflammatory reactions (36). During cerebral ischemia, $N F-\kappa \mathrm{B}$ is activated by inflammatory factors, cytokines, increases in calcium concentration and other factors. After activation, NF- $\kappa \mathrm{B}$ can induce the expression of cytokines, adhesion molecules and inflammatory enzymes, which forms a vicious circle of inflammatory reactions, and cause brain edema and nerve cell damage.

Howard et al (37) found that NF- $\mathrm{BB}$ was rapidly activated at 15-30 min after hypoxia and reoxygenation in human brain microvascular endothelial cells. In this present study, it was found that the nuclear translocation of NF- $\mathrm{NB}$ p65 in $\mathrm{SMS}^{-/-}$mice was significantly less than that in WT mice after ischemia/reperfusion. p65 is an important protein in the NF- $\kappa \mathrm{B}$ signaling pathway, and the entry of p65 from the cytoplasm to the nucleus after phosphorylation is an important marker for activation of NF- $\kappa \mathrm{B}$ signaling (38). This indicated that the lack of SMS2 inhibited the activation of the NF- $\kappa$ B pathway following cerebral ischemia/reperfusion in mice.

In conclusion, a shortage of SMS2 in mice may help to reduce inflammation by inhibiting the activation of the $\mathrm{NF}-\kappa \mathrm{B}$ signaling pathway, and further alleviate cerebral ischemia/reperfusion injury in mice.

\section{Acknowledgements}

Not applicable.

\section{Funding}

No funding was received.

\section{Availability of data and materials}

The datasets used and/or analyzed during the current study are available from the corresponding author on reasonable request.

\section{Author's contributions}

YY, FH and QM conceived and designed the study; collected data; drafted this study; and critically revised the manuscript 
for the important intellectual content. GY analyzed and interpreted the experimental data. QM read and approved the final version of the manuscript. All authors read and approved the final manuscript.

\section{Ethics approval and consent to participate}

The present study was performed with the approval of the Ethics Committee of The Third People's Hospital of Qingdao.

\section{Patient consent for publication}

Not applicable.

\section{Competing interests}

The authors declare that they have no competing interests.

\section{References}

1. Lapi D and Colantuoni A: Remodeling of cerebral microcirculation after ischemia-reperfusion. J Vasc Res 52: 22-31, 2015.

2. Jean WC, Spellman SR, Nussbaum ES and Low WC: Reperfusion injury after focal cerebral ischemia: The role of inflammation and the therapeutic horizon. Neurosurgery 43: 1382-1396, 1998.

3. Wang YS, Li YX, Zhao P, Wang HB, Zhou R, Hao YJ, Wang J, Wang SJ, Du J, Ma LJ, et al: Anti-inflammation effects of oxysophoridine on cerebral ischemia-reperfusion injury in mice. Inflammation 38: 2259-2268, 2015.

4. Xing B, Chen H, Zhang M, Zhao D, Jiang R, Liu X and Zhang S: Ischemic post-conditioning protects brain and reduces inflammation in a rat model of focal cerebral ischemia/reperfusion. J Neurochem 105: 1737-1745, 2008

5. Kolesnick R and Golde DW: The sphingomyelin pathway in tumor necrosis factor and interleukin-1 signaling. Cell 77: 325-328, 1994.

6. Mielke MM, Bandaru VV, Haughey NJ, Rabins PV, Lyketsos CG and Carlson MC: Serum sphingomyelins and ceramides are early predictors of memory impairment. Neurobiol Aging 31: 17-24, 2010.

7. Milhas D, Clarke CJ and Hannun YA: Sphingomyelin metabolism at the plasma membrane: Implications for bioactive sphingolipids. FEBS Lett 584: 1887-1894, 2010

8. Khan M, Sekhon BK, Sekhon CS, Singh I and Singh AK: Sphingolipids in rat model of transient focal cerebral ischemia: Implication for stroke injury. J. Neurochem: Jun 28, 2008 (Epub ahead of print).

9. Tu R, Yang W and Hu Z: Inhibition of sphingomyelin synthase 1 affects ceramide accumulation and hydrogen peroxide-induced apoptosis in Neuro-2a cells. Neuroreport 27: 967-973, 2016.

10. Fikadu Geta T, Philipp T and Holthuis JCM: The multigenic sphingomyelin synthase family. J Biol Chem 281: 29421-29425, 2006.

11. Qin R, Chen ML, Zhu K, Deng JB and Shi YY: Sphingomyelin synthase 2 deficiency decreases atherosclerosis and inhibits inflammation in mice. Sheng Li Xue Bao 62: 333-338, 2010 (In Chinese).

12. Hailemariam TK, Huan C, Liu J, Li Z, Roman C, Kalbfeisch M, Bui HH, Peake DA, Kuo MS, Cao G, et al: Sphingomyelin synthase 2 deficiency attenuates NFkappaB activation. Arterioscler Thromb Vasc Biol 28: 1519-1526, 2008.

13. Gowda S, Yeang C, Wadgaonkar S, Anjum F, Grinkina N, Cutaia M, Jiang XC and Wadgaonkar R: Sphingomyelin synthase 2 (SMS2) deficiency attenuates LPS-induced lung injury. Am J Physiol Lung Cell Mol Physiol 300: L430-L440, 2011.

14. Longa EZ, Weinstein PR, Carlson S and Cummins R: Reversible middle cerebral artery occlusion without craniectomy in rats. Stroke 20: 84-91, 1989.

15. Zhang F, Guo RM, Yang M, Wen XH and Shen J: A stable focal cerebral ischemia injury model in adult mice: Assessment using 7T MR imaging. AJNR Am J Neuroradiol 33: 935-939, 2012.

16. Pérez JM and Pascau J: Image Processing with ImageJ. Packt Publishing, 2016.

17. Livak KJ and Schmittgen TD: Analysis of relative gene expression data using real-time quantitative PCR and the 2(-Delta Delta C(T)) method. Methods 25: 402-408, 2001.
18. Arumugam TV, Okun E, Tang SC, Thundyil J, Taylor SM and Woodruff TM: Toll-like receptors in ischemia-reperfusion injury. Shock 32: 4-16, 2009.

19. Rahimian R, Béland LC and Kriz J: Galectin-3: Mediator of microglia responses in injured brain. Drug Discov Today 23: 375-381, 2018.

20. Fernandes Bertocchi AP,Campanhole G, Wang PH, Gonçalves GM, Damião MJ, Cenedeze MA, Beraldo FC, Teixeira VP, Reis M, Mazzali M, et al: A role for galectin-3 in renal tissue damage triggered by ischemia and reperfusion injury. Transpl Int 21: 999-1007, 2008.

21. Yan YP,Lang BT, Vemuganti R and Dempsey RJ: Galectin-3 mediates post-ischemic tissue remodeling. Brain Res 1288: 116-124, 2009.

22. Song H, Liu S, Zhao Z, Sun W, Wei X, Ma X, Zhao P and Gao D: Increased cycles of DC/CIK immunotherapy decreases frequency of tregs in patients with resected NSCLC. Int Immunopharmacol 52: 197-202, 2017.

23. Liu M, Eguchi N, Yamasaki Y, Urade Y, Hattori N and Urabe T: Focal cerebral ischemia/reperfusion injury in mice induces hematopoietic prostaglandin D synthase in microglia and macrophages. Neuroscience 145: 520-529, 2007.

24. Ohsawa K, Imai Y, Sasaki Y and Kohsaka S: Microglia/macrophage-specific protein Ibal binds to fimbrin and enhances its actin-bundling activity. J Neurochem 88: 844-856, 2010.

25. Yoshinori I and Shinichi KJG: Intracellular signaling in M-CSF-induced microglia activation: Role of Iba1. Glia 40: 164-174, 2002.

26. Wang M, Uchiumi O, Ogiso H, Shui Y, Zou J, Hashizume C, Taniguchi M, Okazaki T and Kato N: Stressful learning paradigm precludes manifestation of cognitive ability in sphingomyelin synthase-2 knockout mice. Behav Brain Res 319: 25-30, 2017.

27. Luberto C, Yoo DS, Suidan HS, Bartoli GM and Hannun YA: Differential effects of sphingomyelin hydrolysis and resynthesis on the activation of NF-kappa B in normal and SV40-transformed human fibroblasts. J Biol Chem 275: 14760-14766, 2000.

28. Liu GJ, Middleton RJ, Hatty CR, Kam WWY, Chan R, Pham T, Harrison-Brown M, Dodson E, Veale K and Banati RB: The $18 \mathrm{kDa}$ translocator protein, microglia and neuroinflammation. Brain Pathol 24: 631-653, 2014.

29. Vegeto E, Belcredito S, Ghisletti S, Meda C, Etteri S and Maggi A: The endogenous estrogen status regulates microglia reactivity in animal models of neuroinflammation. Endocrinology 147: 2263-2272, 2006

30. Moon JB, Lee CH, Park CW, Cho JH, Hwang IK, Yoo KY, Choi JH, Shin $\mathrm{HC}$ and Won $\mathrm{MH}$ : Neuronal degeneration and microglial activation in the ischemic dentate gyrus of the gerbil. J Vet Med Sci 71: 1381-1386, 2009.

31. Lambertsen K, Clausen BH, Babcock AA, Gregersen R, Fenger C, Nielsen HH, Haugaard LS, Wirenfeldt M, Nielsen M, Dagnaes-Hansen F, et al: Microglia protect neurons against ischemia by synthesis of tumor necrosis factor. J Neurosci 29: 1319-1330, 2009.

32. Wong $\mathrm{CH}$ and Crack PJ: Modulation of neuro-inflammation and vascular response by oxidative stress following cerebral ischemia-reperfusion injury. Curr Med Chem 15: 1-14, 2008.

33. Kim S, Kim SY, Pribis JP, Lotze M, Mollen KP, Shapiro R, Loughran P, Scott MJ and Billiar TR: Signaling of high mobility group box 1 (HMGB1) through toll-like receptor 4 in macrophages requires CD14. Mol Med 19: 88-98, 2013.

34. Yang QW, Li JC, Lu FL, Wen AQ, Xiang J, Zhang LL, Huang ZY and Wang JZ: Upregulated expression of toll-like receptor 4 in monocytes correlates with severity of acute cerebral infarction. J Cereb Blood Flow Metab 28: 1588-1596, 2008.

35. Ma Y, He M and Qiang L: Exercise therapy downregulates the overexpression of TLR4, TLR2, MyD88 and NF- $\mathrm{BB}$ after cerebral ischemia in rats. Int J Mol Sci 14: 3718-3733, 2013.

36. Wullaert A, Bonnet MC and Pasparakis M: NF- $\kappa \mathrm{B}$ in the regulation of epithelial homeostasis and inflammation. Cell Res 21: 146-158, 2011.

37. Howard EF, Chen Q, Cheng C, Carroll JE and Hess D: NF-kappa $\mathrm{B}$ is activated and ICAM-1 gene expression is upregulated during reoxygenation of human brain endothelial cells. Neurosci Lett 248: 199-203, 1998.

38. Wagner SA, Satpathy S, Beli P and Choudhary CJEJ: SPATA2 links CYLD to the TNF- $\alpha$ receptor signaling complex and modulates the receptor signaling outcomes. EMBO J 35: 1868-1884, 2016.

This work is licensed under a Creative Commons Attribution-NonCommercial-NoDerivatives 4.0 International (CC BY-NC-ND 4.0) License. 